\title{
Cerebral Venous Thrombosis Presenting in Early Pregnancy Complicated with Nausea and Vomiting: A Single-Institute Consecutive Case series and Literature Review
}

\section{Chuan Wang}

Department of Obstetrics and Gynecology, Ren Ji Hospital, Shanghai Jiao Tong University School of Medicine

Xing Hu

Department of Radiology, Shanghai Ninth People's Hospital, Affiliated to Shanghai Jiaotong University School of Medicine,

Jianhua Lin

Department of Obstetrics and Gynecology, Ren Ji Hospital, Shanghai Jiao Tong University School of Medicine

Ning Zhang ( $\nabla$ ningning1723@126.com)

Department of Obstetrics and Gynecology, Ren Ji Hospital, Shanghai Jiao Tong University School of Medicine

\section{Research Article}

Keywords: Cerebral venous thrombosis, Early pregnancy, Nausea and vomiting, Hyperemesis gravidarum

Posted Date: February 7th, 2022

DOI: https://doi.org/10.21203/rs.3.rs-1317094/v1

License: () (1) This work is licensed under a Creative Commons Attribution 4.0 International License. Read Full License 


\section{Abstract}

Objectives Cerebral venous thrombosis (CVT) is a rare but potentially life-threatening condition in early pregnancy. We sought to describe the manifestation, treatment and outcomes of CVT presenting in early pregnancy through a retrospective consecutive case series in a tertiary referral center, so as to improve the awareness of this rare disease.

Methods Between May 2018 and November 2021, consecutive seven patients with CVT presenting in early pregnancy were enrolled in Ren Ji Hospital, School of Medicine, Shanghai Jiao Tong University. All patients' data like manifestations, laboratory and radiological data, treatment and prognosis were analyzed, and relevant literatures were also reviewed.

Results All seven patients had been suffering from nausea and vomiting accompanied with headache prior to CVT occurrence. The headache was complained aggravation in severity with an average from 3.86 to 7.16 by visual analogue scale over several days. The mean age was $32.4 \pm 2.28$ years, and mean BMI was $21.67 \mathrm{~km} / \mathrm{m}^{2}$. All seven patients showed typical neurological symptoms on admission including epileptic seizures $(n=2,28.6 \%)$, limb weakness ( $\left.n=4,57.1 \%\right)$, aphasia $(n=5,71.4 \%)$, blurred vision $(n=2,28.6 \%)$, disturbed consciousness ( $n=3,42.9 \%)$. Average score was 11.3 points (range from 3 to 15$)$ on Glasgow coma scale (GCS). All patients were diagnosed with CVT at the first visiting day by imaging examinations and multiple venous sinuses thrombosis with average number of 3.7 per patient (range from 2 to 6 ) were confirmed, the most involved was transverse sinus ( $n=7,100 \%$ ), followed by sigmoid sinus ( $n=5$, 71.4\%). All of them was initiated anticoagulation treatment with low-molecular weight heparin (LMWH) instantly as soon as the CVT was defined. Two serious patients underwent catheter thrombolysis or/and decompressive craniotomy, but both still died of CVT deterioration within 5 days of admission. Other five patients were all performed selective induced abortion and was discharged after significant symptomatic improvement. They were remained anticoagulation for one year. At 12-month follow-up, MRI/MRV revealed sinuses were completely recanalized.

Conclusions The present retrospective study should raise awareness of diagnosis and treatment of CVT in nausea and vomiting of early pregnancy complicated with headache. GCS evaluation on admission probably correlated with the prognosis. Neuroimaging remains the cornerstone for the diagnosis and instant anticoagulation prior to severe CVT aggravation is the key for the disease prognosis. Early pregnancy combined with CVT is not a contraindication of continued pregnancy based on the literature review.

\section{Introduction}

Cerebral venous thrombosis (CVT), a rare but potentially life-threatening condition, is more prevalent in females and associated with prothrombotic risk factors such as thrombophilia, antiphospholipid syndrome, trauma, cancer, puerperium and pregnancy [1]. Previous research has generally suggested that the hypercoagulable state of third-trimester pregnancy and puerperium is one of the main pathophysiology associated with pregnancy-related CVT [2], however, CVT is seldom encountered during early pregnancy, thus substantial clinical trials are absent and only a few report cases on pregnancy can be found, resulting in a lack of guidance for these conditions [2]. In the present study we sought to describe the manifestation, treatment and outcomes of CVT presenting in early pregnancy through a retrospective consecutive case series in a tertiary referral center and compared our results with the other case reports published on the subject, in order to improve the awareness of this rare disease. To the best of our knowledge, this is the largest series of CVT presenting in early pregnancy complicated with nausea and vomiting/ hyperemesis gravidarum (NVP/HG) and with the longest post-pregnancy follow-up hitherto reported.

\section{Materials And Methods}

We enrolled seven patients with confirmed CVT in early pregnancy between May 2018 and November 2021, at Ren Ji Hospital, School of Medicine, Shanghai Jiao Tong University. The detailed clinical data of the seven patients were retrospectively reviewed, comparative analysis and close follow-up were performed. This study was conducted following the amended Declaration of Helsinki. Written informed consent was obtained from all participants before inclusion. Furthermore, a systemic literature search regarding CVT in early pregnancy was conducted and totally fifteen patients were included for analysis.

\section{Results}

\section{Patients' basic clinical characteristics}

Clinical features including age, body mass index (BMI), pregnancy and reproduction history, gestation, initial symptoms, time from symptom initiation to admission, and acute neurological symptoms are described in Table 1. The mean age of seven patients was $32.4 \pm 2.28$ years (range $27-42$ years), and mean BMI was $21.67 \mathrm{~km} / \mathrm{m}^{2}$ (range 19.5-23.4 km/m²). All seven patients were within 12 weeks of gestation, five patients (71.45\%) were primiparas. N1 and $\mathrm{N} 2$ (28.57\%) were conceived through assisted reproductive technology. They had not previously been on contraceptive pills, and did not have any personal or family history of venous thrombosis, autoimmune disease, or hematologic disease. The detailed information regarding the initial symptoms, acute neurological symptoms as well as the clinical assay and treatment are summarized as below.

\section{Initial symptoms}

All seven patients had been initially suffering from nausea and vomiting accompanied with headache. Five patients (71.45\%) complained severe nausea and vomiting with 5 to 10 episodes of vomiting daily which unavoidably made normal eating impossible, leading to maternal weight loss, thus hyperemesis gravidarum (HG) was diagnosed and followed by treatment of rehydration in other hospitals. The other two patients complained of mild nausea and vomiting and chose to make minor adjustments on 
daily diet at home. Visual analogue scale (VAS) was used to assess the headache severity of which 0-10 means the severity of pain of which "0" means no such symptoms while " 10 " indicates the most severe symptoms. The headache complained by the patients was mild at the beginning with an average score of 3.86, however, the headache was described as diffuse and aggravation in severity with an average from 3.86 to 7.16 over several days. Time from symptom initiation to admission was 5.7 days (range 3-10 days).

\section{Acute Neurological symptoms}

All seven patients had typical neurological symptoms when they came to our institute due to progressive headache and unresponsive nausea and vomiting. Acute symptoms included epileptic seizures $(n=2,28.6 \%)$, limb weakness $(n=4,57.1 \%)$, aphasia $(n=5,71.4 \%)$, blurred vision ( $n=2,28.6 \%)$, disturbed consciousness ( $n=3,42.9 \%)$. Glasgow coma scale (GCS) was used to estimate the neurological state of these patients. They scored with an average of 11.3 (range 3-15) on the Glasgow coma scale (GCS). There was one patient of N4 (14.2\%) in severe injury with a GCS score lower than 8, and she was transferred to our emergency department with deep coma by other hospital. Two patients of N6 and N7 ( $n=2,28.4 \%)$ was in moderate injury with a GCS score 9-12. Both of N6 and N7 were brought to our emergency department by family members, and N6 was reported with behavioral changes and progressing to a global aphasia, N7 presented with aphasia, confusion, and impaired balance. Four patients of N1, N2, N3 and N5 ( $n=4,71.4 \%)$ were in mild injury with a GCS score 13-15. The clinical symptoms of the involved 7 patients were summarized in Table 1.

\section{Laboratory assay}

All 7 patients were performed with comprehensive laboratory assays as listed in Table 2. Liver and kidney function, thyroid function, echocardiography and electrocardiogram were all normal. A complete blood count, chemistry panel, sedimentation rate, and coagulation function are detected for these patients. Laboratory examination revealed a mild inflammatory response with an elevated WBC count of $14.39 * 10^{9} / \mathrm{L}, \mathrm{D}$-dimer were abnormally elevated to $2.97 \mathrm{mg} / \mathrm{L}$ (range from 0.8 to $11.6 \mathrm{mg} / \mathrm{L}$ ), but coagulation profiles were normal. Screening for thrombophilia including protein C, protein S and homocysteine showed that only protein S is slightly lower in N3 (43.8\%, normal range 50-80\%), and all the coagulation factors were within normal range. Autoimmune diseases with higher risk of hypercoagulation including anticardiolipin antibody, lupus anticoagulant (LA), antinuclear antibody and anti-double strain DNA were also screened and the results showed that only N5 presented with a slightly positive antinuclear antibody (ANA) with 1:160, the rest of the antibody were all negative, and all 7 patients were excluded from autoimmune related disease by rheumatologist. Additionally, N1 and N3 underwent lumbar puncture and elevated opening pressure was revealed but without abnormalities of specific cerebrospinal fluid (CSF).

\section{Neuroimaging examination}

All 7 patients underwent neuroimaging examinations by CT or/and MRI/MRV/MRA for CVT confirmation. Computed tomography scan (CT) was performed on 6 patients $(85.7 \%)$ and revealed cerebral infarction $(n=3,42.9 \%)$, intracranial hemorrhage $(n=3,42.9 \%)$, subarachnoid hemorrhage $(n=3,42.9 \%)$ and encephaledema $(n=3,42.9 \%)$, also hyperdense lesion can be found occasionally in the venous sinus indicating thrombosis. MRI can differentiate CVT from tumor apoplexy, and magnetic resonance venography (MRV) can reveal sinus occlusion. Six patients (85.7\%) were examed by MRV, which demonstrated CVT on all patients and multiple venous sinuses were involved in most of them: the mean involved venous sinuses was 3.7 (range 2-6), the most involved was transverse sinus $(n=7,100 \%)$, followed by sigmoid sinus $(n=5,71.4 \%)$, and the least involved was inferior sagittal sinus ( $n=1,14.3 \%)$, followed by torcular Herophili $(n=2,28.6 \%)$. The imaging features of all seven patients were summarized in Table 3 .

Digital subtraction angiography (DSA) was conducted for patients when there is a need for endovascular minimally invasive surgery. Three patients of N4, N6 and N7 $(n=3,42.9 \%)$ were further proceeded with DSA. DSA confirmed cortical veins and some deep venous structures which CT or MRI/MRV may not reveal, and great cerebral vein thrombosis $(n=2,28.6 \%)$ and internal cerebral vein thrombosis $(n=1,14.3 \%)$ were demonstrated by DSA.

N4 scored 3 (M1V1 E1) points on the GCS. Emergency cranial CT revealed cerebellar hemorrhage and brain stem edema. She was performed with DSA due to rapid neurological deterioration. DSA confirmed occlusion with great cerebral vein, straight sinus, left transverse sinus and sigmoid sinus, thus immediate interventional thrombolysis was performed, a microcatheter was delivered to the distal thrombosed sinus using a microwire from the jugular bulb and thrombolysis with heparin and urokinase was injected, unfortunately, the occluded sinuses were failed to be recanalized, and N4 deteriorated unavoidably and died within four days.

N6 scored 9 (M4V1 E4) points on the GCS. CT showed left frontal lobe and bilateral parietal lobe hemorrhage, subarachnoid hemorrhage with diffused brain swelling. MRI/MRV revealed almost all intracranial venous sinuses and deep internal cerebral veins were occluded. DSA confirmed a complete superficial and deep venous occlusion. As the representative of extremely serious patients, N6 imaging was showed in Figure 1. N6 experienced rapid consciousness deterioration and herniation signs of left pupil dilatation, although endovascular thrombolysis was attempted and emergency decompressive craniotomy was performed, the brain was extremely extensive swollen with diffused thrombosis of the superficial veins. She died four days post-operation.

N7 scored 11 (M6 V1 E4) points on the GCS. CT venography showed hyper density in left transverse sinus, inferior sagittal sinus, straight sinus and sinus confluence. MRI/MRV showed that massive veins including straight sinus, sinus confluence, great cerebral vein, internal cerebral vein and basilar vein were almost completely occluded. DSA indicated that sinus and deep venous were occluded but basal vein and deep vein have been compensated by sylvian vein reflux, thus endovascular thrombolysis or surgical procedure was not further considered.

\section{CVT anticoagulant treatment}

CVT management should be comprehensive including treatment and control of underlying primary disease, thrombolytic and anticoagulant therapy, intracranial pressure reduction, symptom relief and prevention of epilepsy complication. Six patients (85.7\%) received dehydration therapy to depress intracranial pressure. Three patients (42.9\%) received antiepileptic treatment. All 7 patients were initiated anticoagulation treatment with body-weight-adjusted 
subcutaneous low-molecular weight heparin (LMWH) instantly within 12 hours of admission as soon as CVT was defined and obvious intracerebral hemorrhage was excluded. When the patient's convulsions were controlled or complaints improved which was consistent with the neuroimaging alteration indicated by partial recanalization on repeat CT or MRI/MRV, LMWH was substituted with oral warfarin in N1, N2, N3 and N5. Warfarin dose was strictly adjusted based on International Normalized Ratio (INR) with a target of 2.0 to 3.0. The most recent patient N7 was treated with LMWH for two weeks followed by oral rivaroxaban ( $20 \mathrm{mg}$ daily) when her consciousness gradually improved. The period of LMWH bridge to warfarin or rivaroxaban averaged 13.2 days.

\section{Pregnancy outcome and Prognosis}

Of the 7 patients, N4 and N6 died within 5 days after admission due to rapid deterioration, other 5 patients progressed well with significant improvement and discharged finally. All these 5 patients requested induced abortion, thus when they were stabilized by evaluation of multidisciplinary team, therapeutic justifiable abortion were performed with a suspension of anticoagulation for $12 \mathrm{~h}$, and the average days from the admission to abortion was 6.5 days (range 4-13 days). The mean hospitalization of these 5 patients were 21.4 days (range 18-22 days). N2 and N7 experienced almost complete recovery without discomfort, N1 and N5 presented slight visual ghosting, and N3 discharged with one limb slight weakness. The treatment and outcome of the seven patients were summarized in Table 4.

All these discharged 5 patients were remained anticoagulation for one year and close regular follow-up. N1 and N3 patients continued taking antiepileptic drugs and showed good recovery at one-year follow up. At 6-month follow-up, five patients showed no neurologic or functional deficits. At 6 or 12 -month follow-up, MRI/MRV revealed sinuses were recanalized in N2, N3 and N5 as showed in Figure 2.

\section{Literature Review}

In order to accumulate and summarize published case reports or case series regarding CVT in early pregnancy, a systemic literature search was conducted using Medline, Embase and Google Scholar using the relevant keywords: "early pregnancy", "first trimester pregnancy", "cerebral venous thrombosis (CVT)", "intracranial venous thrombosis" as well as combinations of these terms. Studies that involved symptoms and management approach on the CVT presenting in early pregnancy were included in our pooled analysis, and totally fifteen patients were included as showed in Table 5 [3-16]

The first case was reported by Robert in 1957. She was misdiagnosed as nervous breakdown at the beginning, died six hours after admission and was found CVT after autopsy. The first 3 cases reported were diagnosed as CVT after postmortem autopsy (two cases in 1957 and one case in 1978). With the advent and development of imaging modalities, all the following 12 cases were accurately diagnosed with neuroimaging examination and appropriately treated. The mean age of fifteen patients was $28.9 \pm 2.28$ years (range $20-42$ years). Nine patients (60\%) had unremarkable medical history, the other six patients (40\%) had past history of seizure, migraine, antiphospholipid syndrome, oral contraceptive pills, heterozygous factor V Leiden mutation, or CVT. All 15 patients represented typical neurological symptoms, headache is the most common symptom $(n=12,80 \%)$, followed by seizures ( $n=6,40 \%)$, consciousness disorder $(n=3,20 \%)$, aphasia $(n=2,13.3 \%)$ and hemiparesis $(n=2,13.3)$. It is noteworthy that NVP $(n=5,33.3 \%)$ and HG $(n=3,20 \%)$ was also complained in some of those patients. Eleven patients $(73.3 \%)$ received therapeutic anticoagulation, which included systemic heparin, intravenous heparin, subcutaneous injection of LMWH, warfarin, acetylsalicylic acid and eptifibatide. One patient (6.7\%) underwent direct catheter thrombolysis and thrombectomy, two patients (13.3\%) experienced decompressive craniectomy. Eight patients (53.3\%) experienced a complete recovery, the other four patients (26.7\%) showed neurological dysfunction such as one limb weakness, a slight visual field defect, mild neurological deficits and hemiplegia and aphasia. Six patients (40\% $囚 \mathrm{maintained} \mathrm{a}$ delivery until the third trimester, two of them underwent planned Cesarean section and the newborn babies were completely healthy.

\section{Discussion}

CVT, although rare, can occur in early pregnancy. In the present study, we reported a retrospective consecutive case series of CVT presenting in early pregnancy complicated with nausea and vomiting/hyperemesis gravidarum (NVP/HG). NVP is a common condition with prevalence rates for nausea of $50-80 \%$ and for vomiting and retching of 50\%[17]. NVP/HG aggravates dehydration, malnutrition, anemia and further concentration of blood. The Royal College of Obstetricians and Gynecologists' (RCOG) green-top guidelines consider HG a transient risk factor for VTE according to evidence of a general increased risk of VTE for women with HG. Fiaschi L et al reported a population-based cohort study, within 8211850 pregnancies ending in live births or stillbirths, women with $\mathrm{HG}$ had increased odds of venous thromboembolism antenatally (OR 1.94, 99\% $\mathrm{Cl} 1.57,2.39$ for deep vein thrombosis, and OR $2.54,99 \% \mathrm{Cl} 1.89,3.40$ for pulmonary embolism) [18].

The clinical symptoms of CVT are due to two main pathophysiological processes: (1) increased venular and capillary pressure; (2) decreased cerebrospinal (CSF) absorption $[19,20]$. Headache, generally indicative of an increase in intracranial pressure, is the most common symptom in CVT and was present in nearly $90 \%$ of patients [21]. In our study, all 7 CVT patients were initially presented with various degree of headache with an average of 3.86 by VAS. However, NVP/HG with headache findings of patients presents a significant diagnostic challenge, as subjective headache could be the corresponding clinical complaint in NVP/HG, then headache and vomiting aggravated by intracranial hypertension of potential CVT were usually overlooked by obstetricians initially. The headache in present study was described as diffuse and aggravation in severity with an average from 3.86 to 7.16 by VAS over several days. In addition, in the literature review of 15 cases, NVP was found in 5 patients and HG in 2 patients, and headache is the most common symptom ( $\mathrm{n}=12,80 \%$ ). Thus, clinician should prudently differentiate the headache present in the NVP/HG patients, the persistent or aggravated headache could be an initial sign of CVT, early diagnosis and prompt treatment are important to improve prognosis. Besides headache, other neurological symptoms including hemiparesis, aphasia, vertigo, dizziness, seizures, and loss of consciousness appeared successively based on the location of the thrombosis. In this study, time from symptom initiation to hospital admission with multiple neurological symptoms was 5.7 days, a Glasgow Coma Scale score on admission may predict prognosis for CVT patients.

Of the 7 CVT patients, 2 patients were conceived through ART. Thrombophilias are likely to increase thrombotic complications after ovarian stimulation for ART [22]. A meta-analysis comparing pregnancies via ovulation induction to controls found a trend toward increased risk of stroke [23]. Infertility may result

Page $4 / 12$ 
from an underlying risk of vascular disease [24]. The results suggest that infertility may reflect an underlying predisposition to vascular disease and pregnancy can unmask this predisposition in women undergoing IVF or other forms of ART, and NVP/HG present in ART pregnancy could probably further increase the thrombosis risk.

There are still no validated pretest clinical probability scores or laboratory tests that can accurately rule out CVT. Neuroimaging remains the main cornerstone for the diagnosis. A CT scan is a useful initial technique to rule out other acute cerebral disorders and reveal venous infarcts or hemorrhages, but its results can be entirely normal [29]. The golden standard for CVT is the combined visualization of thrombosed vessel or sinus on MRI and absence of the vessel or sinus on MRV [20]. Non-contrast MRI at 3 T or less is considered to be safe during any trimester of pregnancy by both the American Colleges of Radiology (ACR) and Obstetrics and Gynecology (ACOG)in updated guidelines [25]. In light of radiation exposure and contrast agent side effects on pregnancy [33], invasive modality of DSA should be reserved to emergent intervention for thrombolysis or more comprehensive examination is needed for deterioration evaluation. In our cases, CT, MRI/MRV and DSA were performed timely to make a quick and accurate diagnosis as well as treatment evaluation.

According to the International Study on Cerebral Vein and Dural Sinus Thrombosis, the most commonly affected site is the transverse sinus, followed by superior sagittal sinus and straight sinus [26]. Other less common sites are the cortical vein, jugular vein and internal cerebral vein. In most patients, thrombosis occurs in more than one sinus. Our findings are consistent with previous reports. Thrombosis of the deep venous cerebral system veins, internal cerebral veins, vein of Galen, or the straight sinus occurs in approximately $16 \%$ of patients with CVT and is considered a risk factor for poor clinical outcome [15]. Thalamic edema is the imaging hallmark of this condition. Mortality rates among patients with this condition are reported to be between $22 \%$ and $37 \%$ [27]. The clinical features and their severity are highly variable, ranging from isolated headaches to a deep coma, depending on the extent and location of the effected sinus, the venous collateral vessels, and the rate of thrombus progression. The causes of death in our study had two common points (1) low GCS scores at admission (2) extensive deep venous cerebral system embolism with thalamic edema.

According to the guideline of the American Stroke Association/American Heart Association, anticoagulation therapy should be initiated once CVT is diagnosed with no major contraindications [20]. The first line treatment in acute phase usually starts with intravenous heparin or subcutaneous LMWH. The included 7 patients in our study were initiated anticoagulation treatment with body-weight-adjusted subcutaneous LMWH instantly within 12 hours of admission as soon as CVT was defined and obvious intracerebral hemorrhage was excluded. Heparin or LMWH are preferable throughout the pregnancy until delivery as a result of their feature not being transferred into placenta. Oral anticoagulation (vitamin K antagonists and new oral anticoagulants NOAC) is contraindicated during pregnancy, because they cross the placenta and can cause neurodevelopmental disorders and fetal bleeding [28]. The period of oral anticoagulation postpartum varied depending on the etiology of CVT and remains controversial $[9,29]$. In our cases, all the 5 patients were remained anticoagulation for one year since the initial presenting symptom: 4 patients were maintained with oral warfarin to keep a target INR between 2.0 to 3.0 , and the most recent patient N7 with NOAC of rivaroxaban (20 mg daily). Both warfarin and rivaroxaban showed satisfactory effect on anticoagulant maintenance therapy in our cases.

Thrombolytic therapy is usually performed if clinical deterioration occurs despite being on an anticoagulation regime, or elevated intracranial pressure was indicated. A systematic review of CVT cases treated with mechanical thrombectomy, $40 \%$ of who had encephalopathy of coma, reported a mortality of $14 \%$, with worsening or new intracranial hemorrhage in $9 \%$, complete recanalization in $69 \%$, and complete recovery in $35 \%$ [30]. Decompressive craniectomy has shown to be beneficial to critically-ill patients with CVT presenting radiological and clinical features of mass effect with signs of brainstem dysfunction and refractory intracranial hypertension [31]. However, these studies evaluate for outcomes in the general population, and specific analyses regarding pregnant or puerperal populations are limited. In our present study, endovascular thrombolysis was performed on N4 and N6, and N6 was further proceeded with decompressive craniotomy, however, both of them experienced rapid deterioration and died within 3 days of admission.

Although all 5 live patients requested induced abortion in present study, early pregnancy with CVT is not an absolute indication for termination of pregnancy. Based on the literature review of 15 cases, six patients (40\%®maintained a delivery until the third trimester, two of them underwent planned Cesarean section and the newborn babies were completely healthy. Pregnancy requires special attention and consideration of differential treatment options. There is no proven evidence of benefit in abortion regarding the mother's or child's health over not interrupting pregnancy. However, we do recommend a multi-specialty approach where an obstetrics team can decide what is best for the mother's health. Although pregnancy can be maintained, the mother's health should be the priority in case of complications.

\section{Conclusion}

The present retrospective study should raise awareness of diagnosis and treatment of CVT in nausea and vomiting of early pregnancy complicated with headache. Neuroimaging especially MRI/MRV remains the cornerstone for the diagnosis and instant anticoagulation prior to severe CVT aggravation is the key for the disease prognosis. Early pregnancy combined with CVT is not a contraindication of continued pregnancy but should be prudently evaluated by multi-disciplinary team. Larger patient series with a longer follow-up are warranted to draw more definitive conclusions on the subject.

\section{Abbreviations}




\begin{tabular}{ll} 
CVT & Cerebral venous thrombosis \\
\hline NVP & Nausea and vomiting of pregnancy \\
\hline HG & Hyperemesis gravidarum \\
\hline GCS & Glasgow coma scale \\
\hline VAS & Visual analogue scale \\
\hline MRI & Magnetic resonance imaging \\
\hline MRA & Magnetic resonance angiography \\
\hline MRV & Magnetic resonance venogram \\
\hline DSA & Digital subtraction angiography
\end{tabular}

\section{Declarations}

\section{Ethical Approval and Consent to participate}

All procedures performed in studies involving human participants were in accordance with the ethical standards of the institutional and/or national research committee and with the 1964 Helsinki Declaration and its later amendments or comparable ethical standards.

\section{Consent for publication}

Informed consent was obtained from all individual participants included in the study.

\section{Availability of supporting data}

The datasets used and/or analyzed during the current study are available from the corresponding author on reasonable request.

\section{Competing interests}

The authors declared that they have no conflicting interest.

\section{Funding}

This work was supported by Natural Science Foundation of Science and Technology Commission of Shanghai Municipality (No. 16ZR1420000).

\section{Authors' contributions}

Conceived and designed the study: Chuan Wang, Jianhua Lin, Ning Zhang; Collected data: Chuan Wang; Analysed the data: Chuan Wang; Made the figures: Xing Hu; Interpreted the results: Chuan Wang; Wrote the first draft of the manuscript: Chuan Wang, Ning Zhang; Contributed to the writing of the manuscript: Chuan Wang, Ning Zhang. The author(s) read and approved the final manuscript.

\section{Acknowledgements}

We acknowledge all the multidisciplinary members of the obstetrics, interventional radiology, neurosurgery, intensive care unit, imaging department and anesthetics teams for their dedication and support. All the authors would like to thank patients who shared their time and agreed to participate in this study.

\section{References}

1. Pizzi M, Alejos D, Siegel J, Kim B, Miller D, Freeman W: Cerebral Venous Thrombosis Associated with Intracranial Hemorrhage and Timing of Anticoagulation after Hemicraniectomy.Journal of stroke and cerebrovascular diseases : the official journal of National Stroke Association 2016, 25:23122316.

2. Gioti I, Faropoulos K, Picolas C, Lambrou M: Decompressive craniectomy in cerebral venous sinus thrombosis during pregnancy: a case report.Acta neurochirurgica 2019, 161:1349-1352.

3. FISHMAN R, COWEN D, SILBERMAN M: Intracranial venous thrombosis during the first trimester of pregnancy.Neurology 1957, 7:217-220.

4. Lavin P, Bone I, Lamb J, Swinburne L: Intracranial venous thrombosis in the first trimester of pregnancy.Journal of neurology, neurosurgery, and psychiatry 1978, 41:726-729.

5. Dzialo A, Black-Schaffer R: Cerebral venous thrombosis in young adults: 2 Case reports.Archives of physical medicine and rehabilitation 2001, 82:683688.

6. Weatherby S, Edwards N, West R, Heafield M: Good outcome in early pregnancy following direct thrombolysis for cerebral venous sinus thrombosis. Journal of neurology 2003, 250:1372-1373.

7. Hanprasertpong T, Hanprasertpong J, Riabroi K: Cerebral venous sinus thrombosis in early pregnancy: an unusual presentation of primary antiphospholipid syndrome. The journal of obstetrics and gynaecology research 2009, 35:1125-1128. 
8. Dangal G, Thapa L: Cerebral venous sinus thrombosis presenting in pregnancy and puerperium.BMJ case reports $2009,2009$.

9. Munira Y, Sakinah Z, Zunaina E: Cerebral venous sinus thrombosis presenting with diplopia in pregnancy: a case report.Journal of medical case reports $2012,6: 336$

10. Yamamoto J, Kakeda S, Takahashi M, Idei M, Nakano Y, Soejima Y, Saito T, Akiba D, Shibata E, Korogi Y, Nishizawa S: Severe subarachnoid hemorrhage associated with cerebral venous thrombosis in early pregnancy: a case report. The Journal of emergency medicine 2013, 45:849-855.

11. Nie Q, Guo P, Ge J, Qiu Y: Cerebral venous sinus thrombosis with cerebral hemorrhage during early pregnancy.Neurosciences (Riyadh, Saudi Arabia) 2015 , 20:48-51.

12. Maeda Y, Satoh K, Haboshi T, Hanaoka M, Shimada K, Matsuzaki K, Miyake H, Niki H: [A Case Report of Congenital Protein C Deficiency with Cerebral Venous Sinus Thrombosis during Early Pregnancy Period]. No shinkei geka Neurological surgery 2017, 45:913-918.

13. Feng X, Zhao T, Liu J, Zhou C: Cerebral Venous Sinus Thrombosis with Cerebral Hemorrhage Presenting with Status Epilepticus in Early Pregnancy.Clinical laboratory 2018, 64:611-614.

14. Zhang X, Zhang Z, Li N: An Early Pregnant Chinese Woman with Cerebral Venous Sinus Thrombosis Succeeding in Induction of Labor in the Second Trimester.Chinese medical sciences journal = Chung-kuo $i$ hsueh $k^{\prime}$ o hsueh tsa chih 2018, 33:267-271.

15. Serna Candel C, Hellstern V, Beitlich T, Aguilar Pérez M, Bäzner H, Henkes H: Management of a decompensated acute-on-chronic intracranial venous sinus thrombosis. Therapeutic advances in neurological disorders 2019, 12:1756286419895157.

16. Bertani R, Rodrigues R, Koester S, Vasconcelos F, Monteiro R: Complicated Cerebral Venous Thrombosis During the First Trimester of Pregnancy.Cureus 2020, 12:e10683.

17. ACOG Practice Bulletin No. 189: Nausea And Vomiting Of Pregnancy.Obstetrics and gynecology 2018, 131:e15-e30.

18. Fiaschi L, Nelson-Piercy C, Gibson J, Szatkowski L, Tata L: Adverse Maternal and Birth Outcomes in Women Admitted to Hospital for Hyperemesis Gravidarum: a Population-Based Cohort Study.Paediatric and perinatal epidemiology 2018, 32:40-51.

19. Piazza G: Cerebral venous thrombosis.Circulation 2012, 125:1704-1709.

20. Saposnik G, Barinagarrementeria F, Brown R, Bushnell C, Cucchiara B, Cushman M, deVeber G, Ferro J, Tsai F: Diagnosis and management of cerebral venous thrombosis: a statement for healthcare professionals from the American Heart Association/American Stroke Association.Stroke 2011, 42:11581192.

21. Duman T, Uluduz D, Midi I, Bektas H, Kablan Y, Goksel B, Milanlioglu A, Necioglu Orken D, Aluclu U: A Multicenter Study of 1144 Patients with Cerebral Venous Thrombosis: The VENOST Study.Journal of stroke and cerebrovascular diseases : the official journal of National Stroke Association 2017, 26:1848-1857.

22. Ata B, Urman B: Thrombophilia and assisted reproduction technology-any detrimental impact or unnecessary overuse? Journal of assisted reproduction and genetics 2016, 33:1305-1310.

23. Dayan N, Filion K, Okano M, Kilmartin C, Reinblatt S, Landry T, Basso O, Udell J: Cardiovascular Risk Following Fertility Therapy: Systematic Review and Meta-Analysis. Journal of the American College of Cardiology 2017, 70:1203-1213.

24. Roeder H, Lopez J, Miller E: Ischemic stroke and cerebral venous sinus thrombosis in pregnancy. Handbook of clinical neurology 2020, $172: 3-31$.

25. Malaiyandi D, James E, Peglar L, Karim N, Henkel N, Guilliams K: Neurocritical Care of the Pregnant Patient.Current treatment options in neurology 2021, 23:22.

26. Jianu D, Jianu S, Dan T, lacob N, Munteanu G, Motoc A, Băloi A, Hodorogea D, Axelerad A, Pleș H, et al: Diagnosis and Management of Mixed Transcortical Aphasia Due to Multiple Predisposing Factors, including Postpartum and Severe Inherited Thrombophilia, Affecting Multiple Cerebral Venous and Dural Sinus Thrombosis: Case Report and Literature Review.Diagnostics (Basel, Switzerland) 2021, 11.

27. Leach J, Fortuna R, Jones B, Gaskill-Shipley M: Imaging of cerebral venous thrombosis: current techniques, spectrum of findings, and diagnostic pitfalls. Radiographics : a review publication of the Radiological Society of North America, Inc 2006:S19-41; discussion S42-13.

28. Durmuș B, Yperzeele L, Zuurbier S: Cerebral venous thrombosis in women of childbearing age: diagnosis, treatment, and prophylaxis during a future pregnancy. Therapeutic advances in neurological disorders 2020, 13:1756286420945169.

29. Demir C, Inci M, Özkan F, Yıldız M, Özdemir H: Clinical and radiological management and outcome of pregnancies complicated by cerebral venous thrombosis: a review of 19 cases.Journal of stroke and cerebrovascular diseases : the official journal of National Stroke Association 2013, 22:1252-1257.

30. Siddiqui F, Dandapat S, Banerjee C, Zuurbier S, Johnson M, Stam J, Coutinho J: Mechanical thrombectomy in cerebral venous thrombosis: systematic review of 185 cases.Stroke 2015, 46:1263-1268.

31. Ferro J, Crassard I, Coutinho J, Canhão P, Barinagarrementeria F, Cucchiara B, Derex L, Lichy C, Masjuan J, Massaro A, et al: Decompressive surgery in cerebrovenous thrombosis: a multicenter registry and a systematic review of individual patient data.Stroke 2011, 42:2825-2831.

\section{Tables}

Table 1 Basic characteristics and clinical symptoms of included seven pregnancy cases with CVT 


\begin{tabular}{|c|c|c|c|c|c|c|c|c|c|c|c|c|c|}
\hline \multirow[t]{2}{*}{ Patient } & \multirow{2}{*}{$\begin{array}{l}\text { Age } \\
\text { (years) }\end{array}$} & \multirow[t]{2}{*}{$\mathrm{G} / \mathrm{P}$} & \multirow{2}{*}{$\begin{array}{l}\text { BMI } \\
\left(\mathrm{Kg} / \mathrm{m}^{2}\right)\end{array}$} & \multirow{2}{*}{$\begin{array}{l}\text { Gest } \\
\text { week }\end{array}$} & \multirow{2}{*}{$\begin{array}{l}\text { Personal } \\
\text { history }\end{array}$} & \multicolumn{2}{|c|}{ Initial symptoms } & \multirow{2}{*}{$\begin{array}{l}\text { Time from } \\
\text { symptom } \\
\text { initiation } \\
\text { to } \\
\text { admission } \\
\text { (days) }\end{array}$} & \multicolumn{5}{|c|}{ Acute Neurological symptoms at admission } \\
\hline & & & & & & $\mathrm{NVP} / \mathrm{HG}$ & $\begin{array}{l}\text { VAS of } \\
\text { headache }\end{array}$ & & $\begin{array}{l}\text { VAS of } \\
\text { headache }\end{array}$ & $\begin{array}{l}\text { Epileptic } \\
\text { seizures }\end{array}$ & $\begin{array}{l}\text { Limb } \\
\text { weakness }\end{array}$ & Aphasia & $\begin{array}{l}\text { Distu } \\
\text { cons }\end{array}$ \\
\hline N1 & 42 & G1P0 & 20.70 & 5 & IVF & NVP & 3 & 6 & 8 & Yes & Yes & Yes & No \\
\hline N2 & 29 & G2P0 & 19.53 & 7 & IVF & HG & 4 & 3 & 7 & No & Yes & No & No \\
\hline N3 & 32 & G1P0 & 22.03 & 11 & None & NVP & 3 & 7 & 6 & Yes & Yes & No & No \\
\hline N4 & 33 & G5P2 & 22.10 & 8 & None & HG & 5 & 10 & $\begin{array}{l}\text { N/A } \\
\text { (coma) }\end{array}$ & No & No & Yes & Yes \\
\hline N5 & 37 & G3P1 & 22.50 & 8 & None & $\mathrm{HG}$ & 4 & 7 & 8 & No & No & Yes & No \\
\hline N6 & 27 & G1P0 & 21.40 & 8 & None & $H G$ & 4 & 3 & 7 & No & No & Yes & Yes \\
\hline N7 & 27 & G1P0 & 23.40 & 9 & None & $\mathrm{HG}$ & 4 & 3 & 7 & No & Yes & Yes & Yes \\
\hline
\end{tabular}

G/P, Gravidity/Parity; Gest, Gestational; NVP, Nausea and Vomiting of Pregnancy; HG, Hyperemesis Gravidarum;

VAS, Visual analogue scale; N/A, not available; GCS, Glasgow coma scale.

Table 2 Main relevant laboratory tests on hospitalization of included seven pregnancy cases with CVT

\begin{tabular}{|c|c|c|c|c|c|c|c|c|c|c|c|c|c|c|c|}
\hline Patient & $\begin{array}{l}\text { WBC } \\
\left({ }^{*} 10^{9} / \mathrm{L}\right)\end{array}$ & $\begin{array}{l}\text { RBC } \\
\left(* 10^{12} / \mathrm{L}\right)\end{array}$ & $\begin{array}{l}\mathrm{HB} \\
(\mathrm{g} / \mathrm{L})\end{array}$ & Hct & $\begin{array}{l}\text { Platelet } \\
\left(* 10^{9} / \mathrm{L}\right)\end{array}$ & $\begin{array}{l}\text { PT } \\
(\mathrm{S})\end{array}$ & $\begin{array}{l}\text { APTT } \\
(\mathrm{S})\end{array}$ & $\begin{array}{l}\text { D- } \\
\text { dimer } \\
\text { (mg/L) }\end{array}$ & $\begin{array}{l}\text { Hcy } \\
\text { (umol/L) }\end{array}$ & ANA & $\begin{array}{l}\text { anti- } \\
\text { dsDNA } \\
\text { (IU/ml) }\end{array}$ & ACA & LAC & $\mathrm{PS} / \mathrm{PC}$ & CSF \\
\hline N1 & 10.99 & 4.68 & 134 & 0.407 & 225 & 11.3 & 29.2 & 0.8 & 10 & $\mathrm{~N}$ & 21.92 & $\mathrm{~N}$ & $\mathrm{~N}$ & $\mathrm{~N}$ & $\mathrm{~N}$ \\
\hline N2 & 20.33 & 4.39 & 137 & 0.397 & 175 & 10.4 & 26.1 & 1.05 & 8.2 & $\mathrm{~N}$ & 24.98 & $\mathrm{~N}$ & $\mathrm{~N}$ & $\mathrm{~N}$ & N/A \\
\hline N3 & 7.99 & 3.88 & 130 & 0.380 & 184 & 12 & 25.3 & 1.11 & N/A & $\mathrm{N}$ & 21.74 & $\mathrm{~N}$ & $\mathrm{~N}$ & $\begin{array}{l}\text { Low } \\
\text { PS }\end{array}$ & $\mathrm{N}$ \\
\hline N4 & 11.70 & 3.73 & 110 & 0.327 & 182 & 14.3 & 33.2 & 3.8 & N/A & N/A & N/A & N/A & $\mathrm{N} / \mathrm{A}$ & $\mathrm{N}$ & N/A \\
\hline N5 & 14.55 & 4.70 & 137 & 0.390 & 267 & 11.4 & 25.4 & 1.6 & N/A & $1: 160$ & 26.45 & $\mathrm{~N}$ & $\mathrm{~N}$ & $\mathrm{~N}$ & N/A \\
\hline N6 & 24.77 & 4.61 & 137 & 0.379 & 201 & 11.7 & 25.1 & 8.91 & 7.9 & $\mathrm{~N}$ & 21.57 & $\mathrm{~N}$ & $\mathrm{~N}$ & $\mathrm{~N}$ & N/A \\
\hline N7 & 10.40 & 4.60 & 131 & 0.390 & 294 & 12.2 & 25.9 & 0.87 & 6.7 & $\mathrm{~N}$ & 21.22 & $\mathrm{~N}$ & $\mathrm{~N}$ & $\mathrm{~N}$ & N/A \\
\hline
\end{tabular}

WBC, white blood cell; RBC, red blood cell; HB, hemoglobin; Hct, hematocrit; PT, Prothrombin Time;

APTT, activated partial thromboplastin time;Hcy, homocysteine; ANA, antinuclear antibody; anti-dsDNA, anti-double strain DNA;

ACA, anti cardiolipin antibody; LAC, Lupus anticoagulant; PS/PC: Protein S/Protein C; CSF, cerebrospinal fluid; N/A, not available; N, normal.

Table 3 The cranial imaging features of included seven pregnancy cases with CVT

Patient Imaging Modalities Imaging Features

\begin{tabular}{llllll}
$\begin{array}{l}\text { cerebral } \\
\text { infarction }\end{array}$ & $\begin{array}{l}\text { intracranial } \\
\text { hemorrhage }\end{array}$ & $\begin{array}{l}\text { Subarachnoid } \\
\text { hemorrhage }\end{array}$ & encephaledema & Venous Sinuses affected & $\begin{array}{l}\text { Cerebral } \\
\text { vein } \\
\text { thrombosis }\end{array}$ \\
\hline N & Yes & Yes & N & SSS,SS,LTS,RTS, LSS,ISS5 & N \\
\hline N & N & N & N & SSS,RTS,RSS,SS, TH5 & N \\
\hline Yes & N & N & N & SSS,RTS2 & $\begin{array}{l}\text { Cortical } \\
\text { veins }\end{array}$ \\
\hline N & Yes & N & Yes & LTS,LSS,SS3 & GCV \\
Yes & N & Yes & N & LTS,LSS2 & N \\
Yes & Yes & Yes & Yes & SSS,LTS,LSS,RTS,RSS,SS6 & $\begin{array}{l}\text { Cortical } \\
\text { veins }\end{array}$ \\
\hline N & N & N & Yes & SS,ISS,LTS,TH4 & GCV,ICV
\end{tabular}

CTV, CT venography; MRI/MRA/MRV: Magnetic Resonance Imaging/Magnetic Resonance Angiography/Magnetic Resonance Venogram; 
DSA, Digital subtraction angiography; SSS, superior sagittal sinus; SS, straight sinus; ISS, Inferior sagittal sinus; RTS, Right Transverse sinus;

LTS, left transverse sinus; RSS, right Sigmoid sinus; LSS, left Sigmoid sinus; TH, torcular Herophili; GCV, Great cerebral vein;

ICV, Internal cerebral vein; N, normal.

Table 4 Treatment and outcomes of included seven pregnancy cases with CVT

\begin{tabular}{|c|c|c|c|c|c|c|c|c|c|c|c|c|}
\hline \multirow[t]{2}{*}{ Patient } & \multicolumn{2}{|c|}{ Anticoagulation } & \multirow[t]{2}{*}{ Dehydration } & \multirow[t]{2}{*}{$\mathrm{AE}$} & \multirow{2}{*}{$\begin{array}{l}\text { Endovascular } \\
\text { therapy }\end{array}$} & \multirow[t]{2}{*}{ DC } & \multirow{2}{*}{$\begin{array}{l}\text { Abortion } \\
\text { after HA } \\
\text { (days) }\end{array}$} & \multirow{2}{*}{$\begin{array}{l}\text { Pregnancy } \\
\text { termination }\end{array}$} & \multirow{2}{*}{$\begin{array}{l}\text { Hosp } \\
\text { duration } \\
\text { (days) }\end{array}$} & \multirow{2}{*}{$\begin{array}{l}\text { MRI/MRV } \\
\text { before } \\
\text { discharge }\end{array}$} & \multirow{2}{*}{$\begin{array}{l}\text { Symptom } \\
\text { on } \\
\text { Discharge }\end{array}$} & \\
\hline & LMWH & $\begin{array}{l}\text { Bridge to } \\
\text { warfarin/ } \\
\text { rivaroxaban(days) }\end{array}$ & & & & & & & & & & \\
\hline N1 & Yes & 14 & Yes & Yes & $\mathrm{N} / \mathrm{A}$ & $\mathrm{N} / \mathrm{A}$ & 9 & $D \& C$ & 22 & $\begin{array}{l}\text { Partial } \\
\text { Reca }\end{array}$ & $\begin{array}{l}\text { Slight } \\
\text { Visual } \\
\text { ghosting }\end{array}$ & \\
\hline N2 & Yes & 7 & Yes & N/A & $\mathrm{N} / \mathrm{A}$ & N/A & 4 & $D \& C$ & 20 & $\begin{array}{l}\text { Partial } \\
\text { Reca }\end{array}$ & Asym & 1 \\
\hline N3 & Yes & 14 & N/A & Yes & $\mathrm{N} / \mathrm{A}$ & $\mathrm{N} / \mathrm{A}$ & 13 & Misoprostol & 19 & $\begin{array}{l}\text { Partial } \\
\text { Reca }\end{array}$ & $\begin{array}{l}\text { One limb } \\
\text { weakness }\end{array}$ & 1 \\
\hline N4 & Yes & N/A & Yes & $\mathrm{N} / \mathrm{A}$ & Yes & $\mathrm{N} / \mathrm{A}$ & $\mathrm{N} / \mathrm{A}$ & $\mathrm{N} / \mathrm{A}$ & 4 & $\mathrm{~N} / \mathrm{A}$ & death & $\uparrow$ \\
\hline N5 & Yes & 17 & Yes & $\mathrm{N} / \mathrm{A}$ & $\mathrm{N} / \mathrm{A}$ & $\mathrm{N} / \mathrm{A}$ & 5 & $D \& C$ & 22 & $\begin{array}{l}\text { Partial } \\
\text { Reca }\end{array}$ & $\begin{array}{l}\text { Slight } \\
\text { Visual } \\
\text { ghosting }\end{array}$ & $t$ \\
\hline N6 & Yes & N/A & Yes & N/A & Yes & Yes & 1 & $D \& C$ & 5 & $\mathrm{~N} / \mathrm{A}$ & death & $\uparrow$ \\
\hline N7 & Yes & 14 & Yes & Yes & $\mathrm{N} / \mathrm{A}$ & N/A & 7 & $D \& C$ & 18 & $\begin{array}{l}\text { Partial } \\
\text { Reca }\end{array}$ & Asym & 1 \\
\hline
\end{tabular}

AE, Antiepileptic; DC: Decompressive craniectomy; HA, hospital admission; Hosp, hospitalization; FU, follow-up;

D\&C, dilatation and curettage; Reca, recanalization; Asym, Asymptomatic; N/A, not available.

Table 5 Clinical characteristics and outcome of 15 CVT cases in early pregnancy in published literature 


\begin{tabular}{|c|c|c|c|c|c|c|c|c|}
\hline \multirow[t]{2}{*}{ paper } & \multirow[t]{2}{*}{$\begin{array}{l}\text { Age } \\
\text { (years) }\end{array}$} & \multirow[t]{2}{*}{$\mathrm{G} / \mathrm{P}$} & \multirow[t]{2}{*}{$\begin{array}{l}\text { Gest } \\
\text { week }\end{array}$} & \multirow[t]{2}{*}{ Personal history } & \multirow[t]{2}{*}{ Symptom progression } & \multirow[t]{2}{*}{$\begin{array}{l}\text { Imaging } \\
\text { modality }\end{array}$} & \multirow[t]{2}{*}{$\begin{array}{l}\text { Involved } \\
\text { venous }\end{array}$} & \multirow{2}{*}{$\begin{array}{l}\text { treatment } \\
\text { Medical treatr }\end{array}$} \\
\hline & & & & & & & & \\
\hline $\begin{array}{l}\text { Robert } \\
1957^{[3]}\end{array}$ & 20 & N/A & 12 & $\mathrm{~N}$ & Dullness $\rightarrow$ deep coma & $\mathrm{N} / \mathrm{A}$ & $\begin{array}{l}\text { SSS,SS, } \\
\text { TS,TH } \\
\text { (necropsy) }\end{array}$ & $\mathrm{N} / \mathrm{A}$ \\
\hline $\begin{array}{l}\text { Robert } \\
1957^{[3]}\end{array}$ & 27 & N/A & 12 & $\mathrm{~N}$ & NVP,headache $\rightarrow$ seizure $\rightarrow$ deep coma & N/A & $\begin{array}{l}\text { SSS,TH,GCT } \\
\text { (necropsy) }\end{array}$ & N/A \\
\hline $\begin{array}{l}\text { P.J.M } \\
1978^{[4]}\end{array}$ & 42 & G6P1 & 8 & seizure & NVP,headache $\rightarrow$ seizure & N/A & $\begin{array}{l}\text { LTS,RTS, } \\
\text { RSS,LSS } \\
\text { (necropsy) }\end{array}$ & N/A \\
\hline $\begin{array}{l}\text { Dzialo } \\
2001^{[5]}\end{array}$ & 24 & N/A & 12 & migraine & $\begin{array}{l}\text { NVP,headache } \rightarrow \text { dizziness } \rightarrow \text { seizure } \rightarrow \text { Limb } \\
\text { weakness }\end{array}$ & CT,MRI & RTS,RSS,SS & $\begin{array}{l}\text { Systemic hep: } \\
\text { heparin } \rightarrow \text { eno: }\end{array}$ \\
\hline
\end{tabular}

$\begin{array}{llllllll}\text { S.J.M } & 29 & \text { G2P1 } & 9 & \mathrm{~N} & \text { Headache } \rightarrow \text { confused } & \text { CT, } & \text { MRI/MRV }\end{array}$

\begin{tabular}{|c|c|c|c|c|c|c|c|c|}
\hline $\begin{array}{l}\text { Han } \\
2009^{[7]}\end{array}$ & 20 & G1P0 & 10 & $\begin{array}{l}\text { antiphospholipid } \\
\text { syndrome }\end{array}$ & Headache, hemiparesis. & CT,MRI & $\begin{array}{l}\text { SSS,RSS, } \\
\text { RTS }\end{array}$ & $\mathrm{LMWH} \rightarrow$ warf \\
\hline $\begin{array}{l}\text { Dan } \\
2009^{[8]}\end{array}$ & 27 & $\mathrm{G} 2 \mathrm{PO}$ & 10 & OCT & NVP,headache & CT, MRI/MRV & CVT & $\mathrm{LMWH} \rightarrow$ warf \\
\hline $\begin{array}{l}\text { Yus } \\
2012^{[9]}\end{array}$ & 34 & G3P2 & 8 & $\mathrm{~N}$ & HG $\rightarrow$ headache,diplopia & MRI/MRV & RTS,SSS & $\begin{array}{l}\text { intravenous } \\
\text { heparin } \rightarrow \text { LM }\end{array}$ \\
\hline
\end{tabular}

\begin{tabular}{|c|c|c|c|c|c|c|c|c|}
\hline $\begin{array}{l}\text { Yam } \\
2013^{[10]}\end{array}$ & 32 & N/A & 9 & $\mathrm{~N}$ & head dullness $\rightarrow$ headache,fever $\rightarrow$ seizure & CT MRI & $\begin{array}{l}\text { SSS,RTS, } \\
\text { vein of } \\
\text { Galen,SS }\end{array}$ & dehydration \\
\hline $\begin{array}{l}\text { Nie } \\
2015^{[11]}\end{array}$ & 27 & G2P1 & 5 & $\mathrm{~N}$ & Headache, slurred speech & CT,MRI/MRV,DSA & LTS,LSS & $\mathrm{LMWH} \rightarrow$ warf \\
\hline $\begin{array}{l}\text { Mae } \\
2017^{[12]}\end{array}$ & 35 & G5P1 & 8 & $\mathrm{~N}$ & Seizures & MRI/MRV & SSS,RTS & $\begin{array}{l}\text { intravenous } \\
\text { heparin } \rightarrow \text { LMI }\end{array}$ \\
\hline $\begin{array}{l}\text { Fen } \\
2018^{[13]}\end{array}$ & 32 & G2P1 & 10 & $\mathrm{~N}$ & headache $\rightarrow$ Seizures $\rightarrow$ unconsciousness & CT, MRI/MRV & RTS,RSS & LMWH \\
\hline $\begin{array}{l}\text { Zha } \\
2018^{[14]}\end{array}$ & 22 & G1P0 & 10 & migraine & NVP,headache & CT, MRI/MRV & SSS,RTS & LMWH $\rightarrow$ warf \\
\hline $\begin{array}{l}\text { Ser } \\
2019^{[15]}\end{array}$ & 34 & G2P1 & 10 & $\begin{array}{l}\text { heterozygous } \\
\text { factor V Leiden } \\
\text { mutation,CVT }\end{array}$ & $\begin{array}{l}\text { HG,headache } \rightarrow \text { motor aphasia } \rightarrow \text { global } \\
\text { aphasia }\end{array}$ & MRI & $\begin{array}{l}\text { All venous } \\
\text { sinuses and } \\
\text { deep } \\
\text { internal } \\
\text { cerebral } \\
\text { veins }\end{array}$ & $\mathrm{LMWH} \rightarrow$ ASA. \\
\hline $\begin{array}{l}\text { Ber } \\
2020^{[16]}\end{array}$ & 28 & N/A & 9 & $\mathrm{~N}$ & $\mathrm{HG} \rightarrow$ confusion, and impaired balance. & CT & RTS,LTS & heparin $\rightarrow$ oral \\
\hline
\end{tabular}

G/P, Gravidity/Parity; Gest, Gestational; NVP, Nausea and Vomiting of Pregnancy; HG, Hyperemesis Gravidarum; DC: Decompressive craniectomy;

OCT, oral contraceptive. SSS, superior sagittal sinus; SS, straight sinus; ISS, Inferior sagittal sinus; RTS, Right Transverse sinus;

LTS, left transverse sinus; RSS, right Sigmoid sinus; LSS, left Sigmoid sinus; TH, torcular Herophili; GCT, Great cerebral vein; N/A, not available.

\section{Figures}



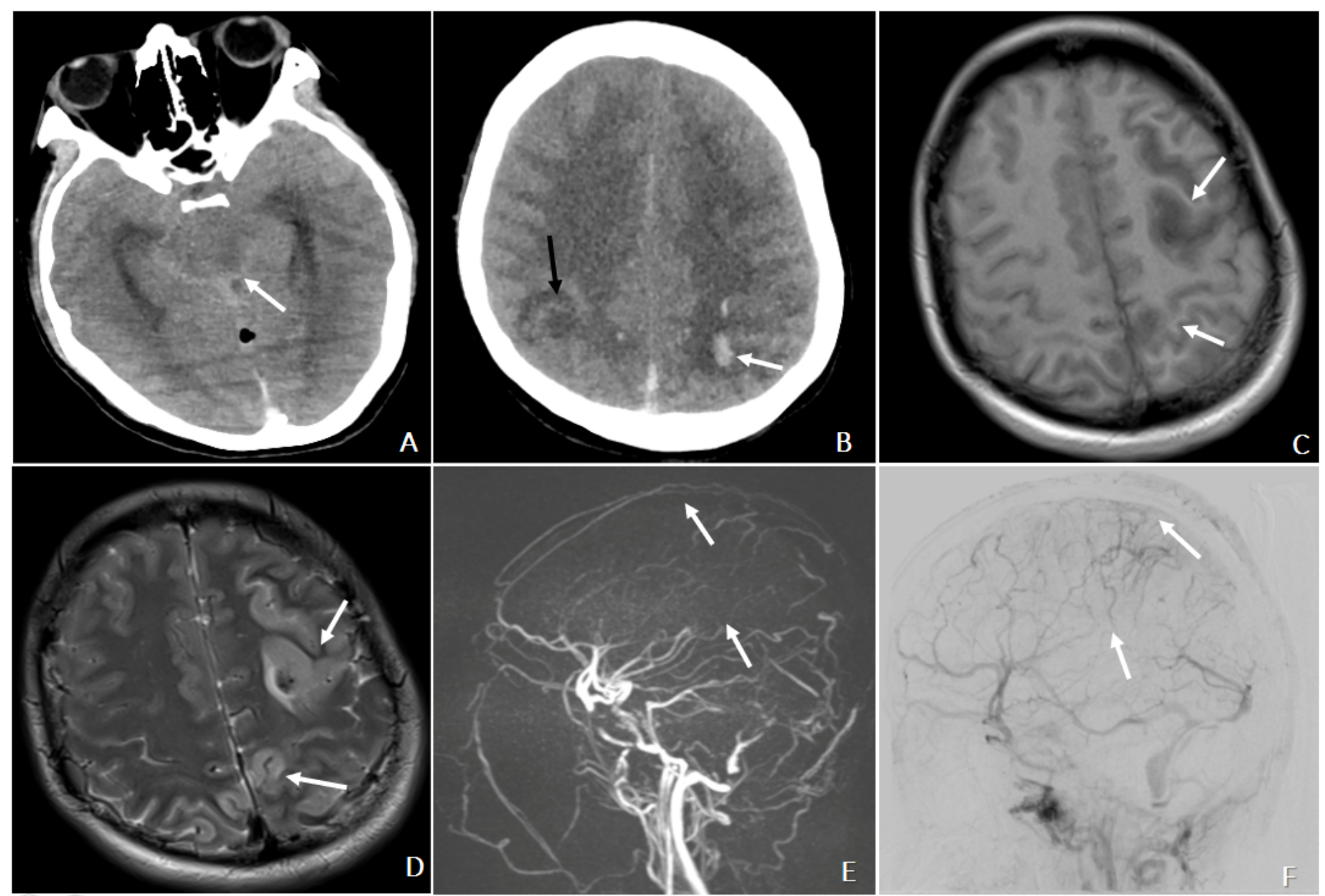

Figure 1

Imaging features of CVT on the representative N6 case with extremely serious manifestation. (A) None-contrast CT showed brain swelling and ambient cisterns compression (white arrow); (B) CT showed multiple ischemic infarctions (black arrow) with a hemorrhagic component (white arrow);(C) MRI showed the lesion appears hyperintense surrounded by a large hypointense area on T1-weighted MRI; (D) MRI showed hypointense surrounded by a large hyperintense area on T2-weighted MRI; (E) MRV showed complete occlusion of superior sagittal sinus (superior arrow) and inferior sagittal sinus (inferior arrow);(F) DSA demonstrated occlusion of superior sagittal sinus (superior arrow) and inferior sagittal sinus (inferior arrow). 


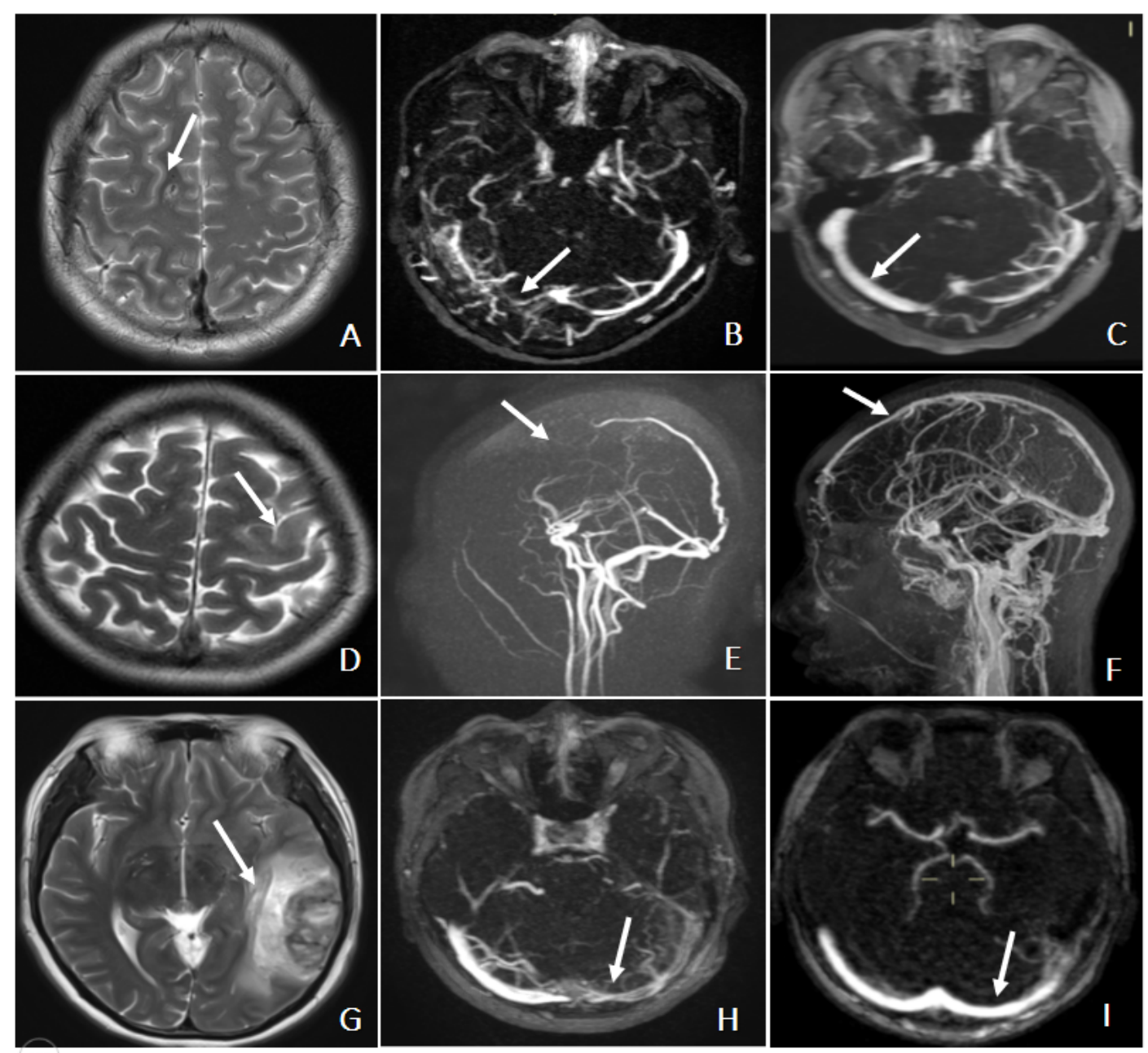

Figure 2

Improvement of imaging features of 3 representative cases on admission and discharge follow-up. N2 patient: (A) MRI upon admission showed hyperintense lesion on the right frontal lobe on T2-weighted MRI; (B) MRV upon admission revealed occlusion of the right transverse sinus; (C) MRV at 6 months follow-up demonstrated recanalization of the right transverse sinus. N3 patient: (D) MRI upon admission showed hyperintense lesion on the left frontal lobe on T2weighted MRI; (E) MRV upon admission revealed occlusion of the superior sagittal sinus and cortical vein; (F) MRV at 12-month follow-up demonstrated recanalization of the superior sagittal sinus and cortical vein. N5 patient: (G) MRI upon admission showed hyper-and hypo-density lesion on the left temporal lobe on T2-weighted MRI; (H) MRV upon admission revealed occlusion of left transverse sinus; (I) MRV at 6 months follow-up demonstrated recanalization of left transverse sinus.

\section{Supplementary Files}

This is a list of supplementary files associated with this preprint. Click to download.

- Supplementary.docx 